\title{
A emergência da História Agrária - resenha de Formação social da miséria no sertão do São Francisco (1820-1920) | Francisco Carlos Teixeira da Silva
}

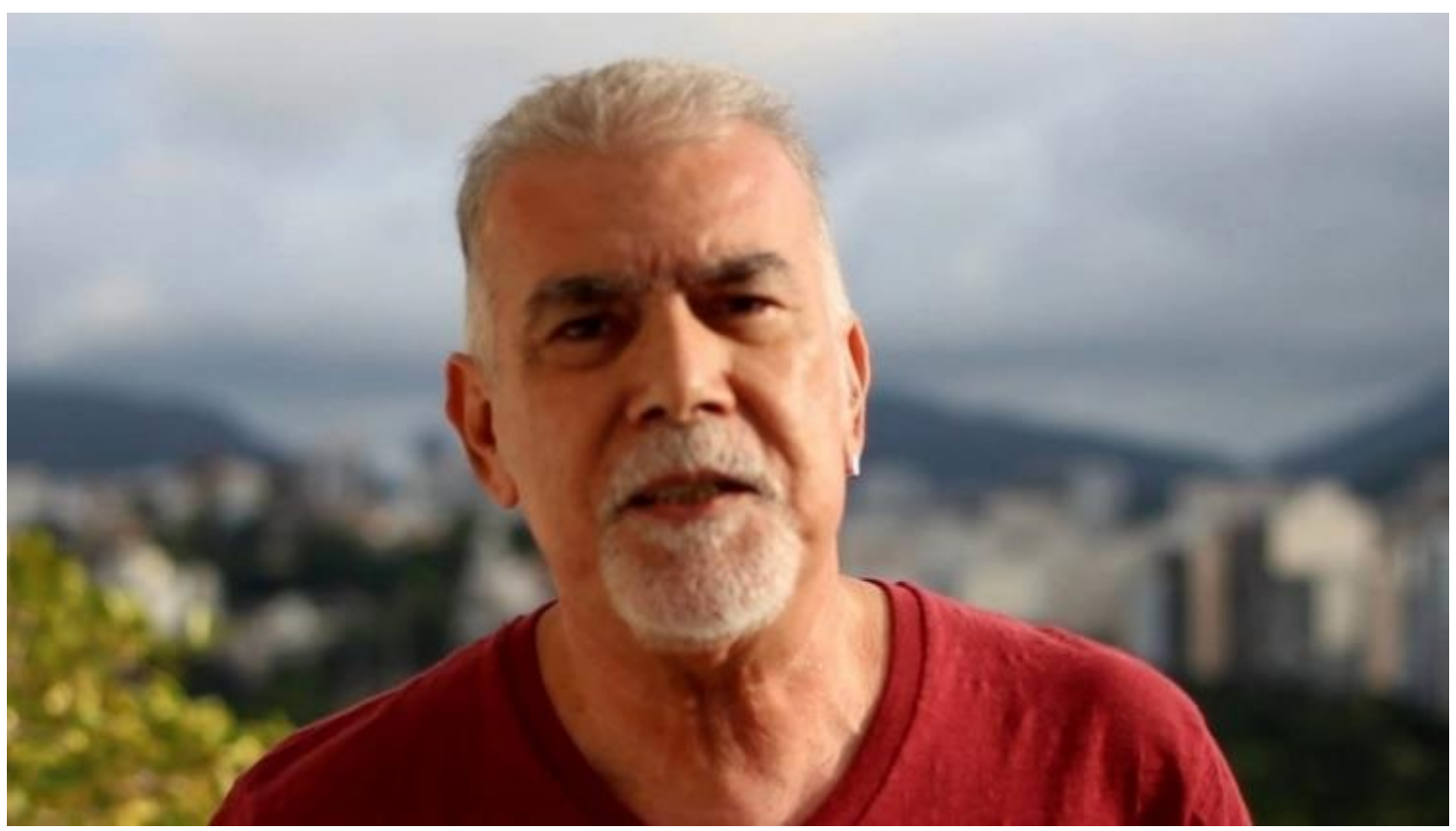

SOS Brasil Soberano - 2017

A publicação Formação social da miséria no sertão do São Francisco (1820-1920), do professor Francisco Carlos Teixeira da Silva (UFRJ) é uma notícia alvissareira para os estudiosos da historiografia sergipana. Chico Carlos, como é carinhosamente conhecido, produziu o texto como dissertação de mestrado, há mais de quatro décadas, sob orientação de Maria Yedda Linhares. Hoje, Chico Carlos é lembrado pelos estudos sobre História Contemporânea e História do Tempo Presente e é provável que alguém estranhe a relação entre o autor e os estudos sobre a história social da agricultura. 


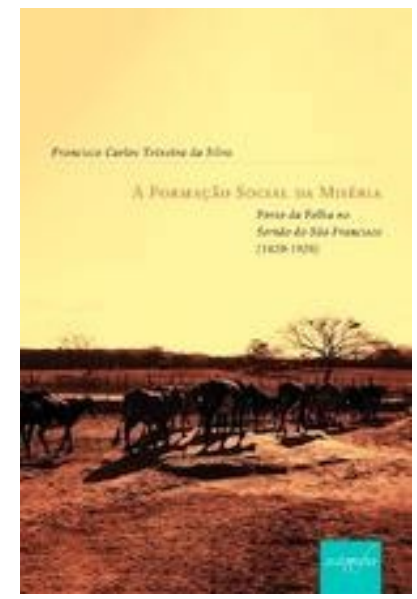

A distância entre a defesa, ocorrida em 1981, e o lançamento desse livro em primeira edição (2018) é reveladora dos avanços da pesquisa histórica em Sergipe com a consolidação dos cursos de pós-graduação na área de história e ciências sociais. Em parte, suas críticas à produção historiográfica da época foram superadas, especialmente no que se refere à abordagem da história social e cultural do Estado. Nesse sentido, o livro é exemplar para o estudante universitário que se debruça sobre a história da historiografia sergipana, pois é tributário da produção brasileira dos anos 1970 e 1980, quando o uso das fontes e a utilização dos métodos da História Agrária contribuíram, significativamente, para a análise da formação do mercado interno e da produção de alimentos no Brasil, com os trabalhos seminais de Maria Yedda Linhares e Ciro Flamarion Cardoso, que retornavam do exílio para o convívio acadêmico nacional.

Como a estrutura de posse e uso da terra é expressão das relações sociais de produção e da estrutura de classes, o livro serve de ponta de lança para refletir os dramáticos conflitos sociais na centúria proposta como periodização, a partir do primeiro censo da Freguesia de São Pedro de Porto da Folha (1820) e o primeiro recenseamento agrícola do Brasil (1920). Esse momento é fundamental para entendermos o processo de "formação social da miséria" no Sertão do São Francisco, com o avanço das fazendas de gado sobre a pequena produção camponesa, sob a liderança da oligarquia pecuarista.

A mudança do uso da "terra de refúgio e trabalho", ocupada por remanescentes dos povos originários, quilombolas e um vigoroso pequeno estrato de pequenos produtores, para a "terra de negócio", das fazendas de gado "à solta" serve para compreender a origem social da miséria na região, com a submissão da pequena propriedade aos interesses pecuaristas. $\mathrm{O}$ conflito entre camponeses e criadores tem como resultado a extinção das terras comunais (heréus, como eram conhecidas), destruindo a "intensa vivência comum entre negros, índios e brancos pobres" pelo fato de que as terras do Morgado de Porto da Folha não poderiam ser compradas ou vendidas, sendo "apossadas em comum pelas diversas famílias camponesas" (p. 76 e 77).

Da precária e diversificada documentação histórica relativa à Sergipe, o historiador demonstrou, de modo cabal, que a história do Sertão "é largamente uma série de expropriações sucessivas das terras dos primeiros posseiros" (p. 130). No caso do Sertão do São Francisco, aos poucos uma poderosa oligarquia de criadores de gado, capitaneada pelas famílias Alves, Feitosa e Britto, açambarcou terras locais de melhor qualidade, como o Aldeamento dos Índios da ilha de São Pedro, entre outras, em um conluio entre os representantes canavieiros do Vale do Cotinguiba e os do Hinterland pecuarista.

Nesse processo de luta pelo uso da terra e das fontes de produção de água com os plantadores de algodão e os criadores de gado, a variedade de cultivos agrícolas cedeu ao sistema de algodão-gado, produzindo uma camada mínima de homens ricos, que representavam a classe dominante sertaneja, controladora da política local. O monopólio da família Britto sobre boa parte das atividades pecuaristas à época representava a "imensa dependência dos grupos dominantes ao monopólio da terra", conseguido "através de mecanismos de coerção e expropriação nitidamente extra econômicos" (p. 94). Esses mecanismos foram decisivos na diminuição absoluta do rebanho suíno, 
central na estratégia de manutenção dos camponeses, com a assunção de ovinos e caprinos como alternativa aos dominados, pois eram mais aptas às novas frentes de expansão em terras mais áridas ou semiáridas de Poço Redondo e Canindé do São Francisco, para onde foram empurrados os camponeses.

Na segunda metade do século XIX, com as epidemias de cólera e da fome, surtos de banditismo emergiram na região, fazendo com que as autoridades expressassem a necessidade do "enquadramento dos pobres", colocados como fonte da morbidez, da agitação e da intranquilidade. Além da necessária ajuda aos pobres e flagelados, "alguns ilustrados de Porto da Folha e de Gararu não hesitaram em dar ao crime e a violência o status de traço de caráter sertanejo" (p. 214). Sem dúvida, essas condições pavimentariam a adesão aos grupos de cangaceiros ou mesmo às tropas volantes, quando da chegada de Lampião à região no final dos anos 1920 e por toda a década de 1930.

A ideia de frentes de trabalho foi uma das opções de enfrentamento da seca no sertão do São Francisco, antecipando ações governamentais que marcariam todo o século XX. No caso de Porto da Folha, a prefeitura contratou 77 trabalhadores que eram pagos com porções de farinha, em 1890 (p. 202). Essas ações, entretanto, não foram suficientes para amainar a fome e os grupos dominantes solicitaram reforços policiais para $\mathrm{o}$ controle da população esfomeada que ameaçava a ordem latifundiária.

Portanto, além da expropriação cotidiana das terras e da construção de corpo legal das autoridades municipais, vinculadas aos criadores de gado, ao camponês restava poucas opções: ou se submetia ao serviço dos grandes proprietários ou, "expulsos como camponeses, voltariam como flagelados, mendigos e ladrões para os quais havia os campos de trabalho e a prisão" (p. 210).

Ao tomar partido de denunciar a miséria nos sertões do São Francisco nos anos 1970, o historiador respondia às questões do tempo presente em que foi escrita a dissertação, quando militantes da Igreja católica desenvolviam importante trabalho de organização dos trabalhadores rurais e de luta pela reconquista das terras indígenas na ilha de São Pedro.

Entretanto, apesar de seu compromisso ético-político, não compreendi a exclusão no formato de livro do capítulo correspondente à morte dos índios, que correspondia ao capítulo VI da segunda parte do trabalho original. Mesmo que alguns dados já estivessem colocados na parte I, capítulo 1 , o processo de extinção dos índios na Câmara municipal de Porto da Folha, em 1887 e 1888, sob o controle do Coronel João Fernandes de Brito, expôs os lucros conseguidos, conforme documento de 1915, por parte dos apropriadores das terras indígenas, como as famílias Britto, Seixas, Fernandes da Silva e Alves de Lima e Silva (p. 181).

Essa opção não oblitera a contribuição do historiador em explicitar que a formação social da miséria nos sertões brasileiros está umbilicalmente ligada à ausência de democratização ao acesso da terra, tão bem sintetizada em outro livro do autor e da professora Maria Yedda Linhares, Terra Prometida: Uma história da questão agrária no Brasil (1999). Por certo, os sertões do São Francisco passaram por recentes e intensas transformações econômicas, sociais e culturais, mas, ao ler esse livro, penso que a "modernização sem mudança" mantém uma das "dívidas sociais" mais persistentes na história brasileira sem perspectiva de solução: a questão agrária. 
Sumário de Formação social da miséria no sertão do São Francisco (1820-1920)

- Agradecimentos (Em 1981)

- Apresentação à edição de 2018

- História Agrária, uma opção metodológica

- A Historiografia Sergipana (Nota historiográfica em 1980)

- Parte I. A terra ou a formação social da miséria

1. Terra de refúgio

2. Terra de trabalho

3. Terra de negócio

- Parte II. Os homens ou dos camponeses e criadores

1. Problemas da demografia no Brasil e em Sergipe

2. De quantos homens se fala ou da "solidão dos nossos campos"

3. A morbidade e a morte no sertão do São Francisco - ou a espantosa morte das crianças

4. Homens livres

5. A escravidão sertaneja

- Parte III. A luta ou a maré da miséria

1. Os modos de existência: tentativa de uma análise sócioprofissional para o sertão do São Francisco

2. A seca

3. A maré da miséria

- Conclusão

- Fontes e bibliografia

- Anexos 


\section{Resenhista}

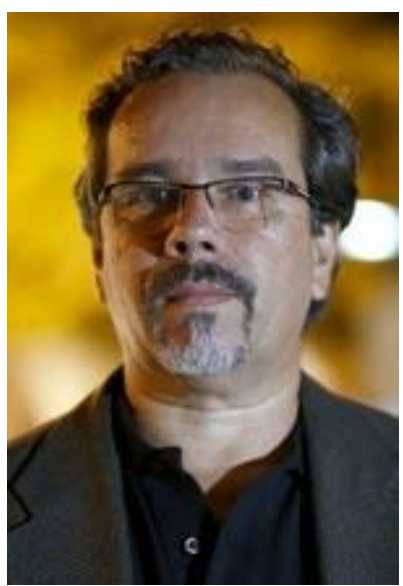

Antônio Fernando de Araújo Sá - Doutor em História pela Universidade de Brasília (UnB), professor do Departamento de História e do Mestrado em História da Universidade Federal de Sergipe e editor da Ponta de Lança - Revista Eletrônica de História, Memória \& Cultura. Publicou, entre outros títulos, Rio Sem História? Leituras sobre o Rio São Francisco (2018) e Entre sertões e representações: ensaios e estudos (2021). E-mail: fernandosa1965@gmail.com.

\section{Para citar esta resenha}

SILVA, Francisco Carlos Teixeira da. Formação Social da Miséria: Porto da Folha no Sertão do São Francisco (1820-1920). Rio de Janeiro: Autografia, 2018. 194p. Resenha de: SÁ, Antonio Fernando de Araújo. A emergência da História Agrária. Crítica Historiográfica. Natal, v.1, n.2, nov./dez. 2021.

\section{Baixar esta resenha em PDF}

(C) - Os autores que publicam em Crítica Historiográfica concordam com a distribuição, remixagem, adaptação e criação a partir dos seus textos, mesmo para fins comerciais, desde que lhe sejam garantidos os devidos créditos pelas criações originais. (CC BY$\mathrm{SA})$ 